\section{Meta-analysis of randomised controlled trials comparing latanoprost with timolol in the treatment of patients with open angle glaucoma or ocular hypertension}

\author{
W Y Zhang, A Li Wan Po, H S Dua, A Azuara-Blanco
}

Glaucoma is one of the most frequent causes of blindness in the industrialised world. The economic burden including direct and indirect costs of the disease in the UK was estimated to be $£ 132$ million in $1990 .^{1}$ The mainstay of drug treatment for glaucoma is timolol, a topical $\beta$ blocker. However, $\beta$ blockers are contraindicated in patients with cardiovascular or pulmonary disorders. ${ }^{2-4}$ Pilocarpine, a cholinergic agonist, is sometimes used but it needs to be administered four times per day and causes miosis, myopia, and occasionally retinal detachment and progressive closure of the anterior chamber angle. ${ }^{56}$ Given such problems, the search for new effective and safer antiglaucoma agents continues. Among the recently introduced agents, three are widely used as alternatives when $\beta$ blockers are contraindicated or fail to control intraocular pressure-latanoprost (a prostaglandin $\mathrm{F}_{2 \alpha}$ analogue), dorzolamide (a topical carbonic anhydrase inhibitor), and brimonidine (a selective $\alpha_{2}$ agonist). Latanoprost appears highly promising because of its comparable or better efficacy when compared with timolol. We therefore undertook a comparison of the effects of topical latanoprost and timolol on intraocular pressure (IOP) based on published randomised controlled trials conducted by both pharmaceutical companies and academics.

\section{Materials and methods}

RETRIEVAL OF PUBLISHED STUDIES

Reports of randomised controlled trials (RCTs) of latanoprost versus timolol were identified through a systematic search consisting of: (1) an electronic search of Medline, Embase, and Scientific Citation Index; (2) searches of reference lists of original reports and review articles, retrieved through the electronic searches; (3) searches for manufacturers' databases including Pharmacia Upjohn ophthalmology database and Merck glaucoma database. The computerised searches covered the period 1966 to end of July 2000.

The medical subject heading $(\mathrm{MeSH})$ search used in Medline and Embase consisted of three stages, each contained any possible $\mathrm{MeSH}$ relevant to the target diseases, drugs, and study methods as shown in Table 1. All $\mathrm{MeSHs}$ were exploded. Three stages were then combined to produce citations associated with randomised controlled trials of latanoprost and timolol in the treatment of glaucoma. patients is still justified.

(Br F Ophthalmol 2001;85:983-990) 
Table 1 MeSH search strategy

\begin{tabular}{|c|c|c|c|c|c|}
\hline \multicolumn{2}{|c|}{ Stage 1 Diseases } & \multicolumn{2}{|c|}{ Stage 2 Drugs } & \multicolumn{2}{|c|}{ Stage 3 Study methods } \\
\hline 1 & exp glaucoma ${ }^{\star}$ or exp glaucoma, open angle ${ }^{\star}$ & 4 & exp prostaglandins $\mathrm{F}$, synthetic ${ }^{\star}$ & 7 & exp clinical trials ${ }^{\star}$ or exp randomised controlled trials ${ }^{\star}$ \\
\hline 2 & exp ocular hypertension $\star$ & 5 & exp adrenergic $\beta$ antagonists ${ }^{\star}$ & 8 & exp double blind method ${ }^{\star}$ \\
\hline 3 & 1 or 2 & 6 & 4 and 5 & $\begin{array}{l}9 \\
10 \\
11\end{array}$ & $\begin{array}{l}\text { exp single blind method }{ }^{\star} \\
\text { exp random allocation }{ }^{\star} \\
7 \text { or } 8 \text { or } 9 \text { or } 10\end{array}$ \\
\hline
\end{tabular}

Finally, we combined three stages together using: 3 and 6 and 11

A keyword search was undertaken in the Scientific Citation Index using the words glaucoma/ocular hypertension, latanoprost/ prostaglandin ${ }^{\star}$, timolol/beta-blocker ${ }^{\star} /$ beta blocker ${ }^{\star} / \beta$-blocker ${ }^{\star} / \beta$ blocker ${ }^{\star}$. We then $\mathrm{read}$ the titles and abstracts of retrieved citations to identify possible RCTs. We also wrote to the manufacturers with our final lists to identify other possible RCTs which our searches failed to identify.

INCLUSION AND EXCLUSION CRITERIA

Only randomised controlled trials directly comparing latanoprost with timolol were included. To facilitate interpretation only studies undertaken in open angle glaucoma (including primary and secondary open angle glaucoma) or ocular hypertension were included.

QUALITY ASSESSMENT

Quality of studies was assessed based on randomisation, masking, and withdrawal as proposed by Jadad. ${ }^{7}$ However, we did not allocate any additional score to an RCT according to whether it described the method of randomisation. In our view, this is a feature of the reporting of the trials and allocation of additional points may be arbitrary. A randomised study was defined as one in which the investigators reported it as being randomised

\begin{tabular}{|c|c|}
\hline \multicolumn{2}{|l|}{$\begin{array}{l}\text { Potentially relevant } F \\
\text { screened for retrieva }\end{array}$} \\
\hline 1 & $\begin{array}{l}\text { RCT excluded, because of closed angle glaucoma } \\
(n=1)^{13}\end{array}$ \\
\hline \multicolumn{2}{|c|}{$\begin{array}{l}\text { RCTs retrieved for more detailed } \\
\text { evaluation }(n=24)^{14-37}\end{array}$} \\
\hline & $\begin{array}{l}\text { RCTs excluded, because of non-comparison } \\
\text { between latanoprost versus timolol }(n=5)^{14-18}\end{array}$ \\
\hline \multicolumn{2}{|c|}{$\begin{array}{l}\text { Potentially appropriate RCTs to be include } \\
\text { in the systematic review }(n=19)^{19-37}\end{array}$} \\
\hline & $\begin{array}{l}\text { RCTs excluded, because of duplication }(n=3),{ }^{19-2} \\
\text { other outcomes }(n=2)^{22-23}\end{array}$ \\
\hline \multicolumn{2}{|c|}{$\begin{array}{l}\text { RCTs included in the systematic review } \\
(n=14)^{24-37}\end{array}$} \\
\hline I & $\begin{array}{l}\text { RCTs excluded from primary pooling of efficacy } \\
\text { data, because of follow up studies after RCTs } \\
(n=3)^{24-26}\end{array}$ \\
\hline
\end{tabular}

Figure 1 Flow of the RCTs included in our systematic review. without necessarily defining the randomisation method explicitly since in the past this was not a requirement in the reporting of RCTs. Masking was differentiated as double blind, single blind and open label. Parallel and crossover designs were also categorised. The percentage of withdrawals was calculated. The impact of all these quality components on our metaanalysis was assessed using sensitivity analysis.

\section{DATA EXTRACTION}

Two of us (WYZ, ALWP) undertook data extraction independently. Any disagreement was resolved by discussion. A customised form was used to record the authors of the study, the year of publication, design of trial (double blind or single blind, parallel or crossover), location of trial, length of study, number of subjects, patient age, sex, type of glaucoma, baseline IOP, and end point IOP. In addition, we recorded the proportion of withdrawals, number of patients reporting local side effects (such as hyperaemia, conjunctivitis, and increased iris pigmentation) and systemic side effects (such as bradycardia, hypotension, and headache).

\section{STATISTICAL ANALYSIS}

We abstracted the mean and standard error of the IOP at baseline and end point from individual studies to calculate the mean IOP reduction $(I O P R)$ and within group standard error $\left(S E_{I O P R}\right)$ using

$$
\begin{aligned}
& I O P R=I O P_{\text {baseline }}-I O P_{\text {endpoint }} \\
& S E_{I O P R}=\sqrt{S E_{\text {baseline }}^{2}+S E_{\text {endpoint }}^{2}}
\end{aligned}
$$

The percentage IOP reduction (IOPR\%) and its standard error $\left(S E_{I O P R \%}\right)$ was then estimated by $I O P R \%=I O P R / I O P_{\text {baseline }}$ and $S E_{\text {IOPR\% }}=S E_{\text {IOPR }} / I O P_{\text {baseline }}$

The difference of the IOP reduction and its standard error between treatment groups was then calculated for each individual study. For estimating the weighted pooled difference in effect, the method previously described by us was used. ${ }^{8}$

The relative risk (RR), risk difference (RD), and number needed to harm (NNH) were estimated for the adverse effects using intention to treat analysis. Interval estimation of relative risk and risk difference were as described by Rothman. ${ }^{9}$ In the pooling of relative risk and risk difference, the method described by DerSimonian and Laird $^{10}$ was used. The number needed to harm and its 95\% confidence intervals $(95 \% \mathrm{CI})$ were estimated as described by Cook. ${ }^{11}$ 


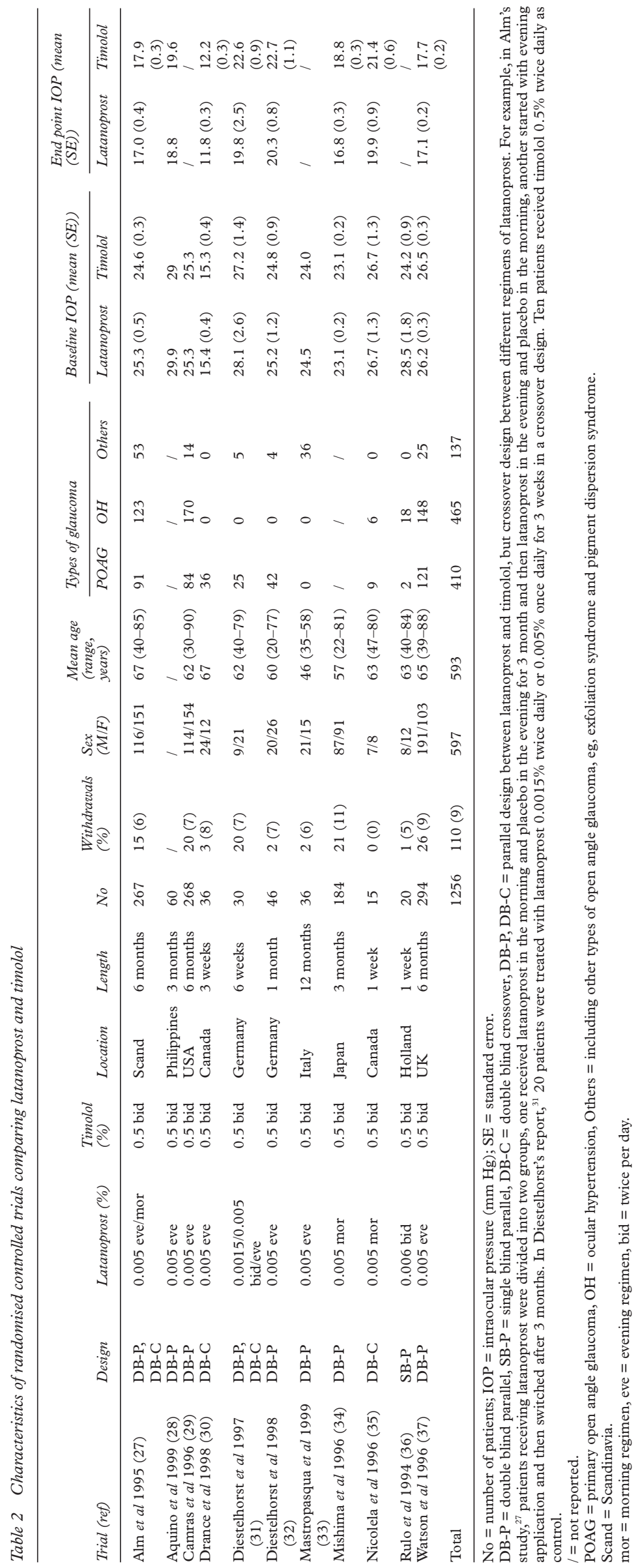

A random effects model was used if trials were heterogeneous on the basis of the $Q$ statistic for heterogeneity ${ }^{12}$ and the reason for the heterogeneity could not be identified.

In addition, to compare latanoprost and timolol, the study also investigated the effects of the evening regimen, morning regimen, and twice daily regimen of latanoprost in reducing IOP.

\section{Results}

CHARACTERISTICS OF TRIALS

Twenty five potential RCTs associated with latanoprost and timolol in the treatment of glaucoma were identified through the literature search. ${ }^{13-37}$ Eleven of them met our inclusion criteria. ${ }^{27-37}$ The flow of the RCTs included in our analysis is shown in Figure 1.

Randomised controlled trials included were undertaken in various countries including the USA, Canada, Japan, the UK, other European nations, and Scandinavia (Table 2). There were eight double blind parallel studies, two double blind crossover studies, and one single blind parallel studies. Five are multicentre RCTs. ${ }^{28} 30323437$ Length of studies varied from 1 week to 1 year. Latanoprost $0.005 \%$ or $0.006 \%$ eye drops were directly compared with timolol $0.5 \%$ eye drops in all of the studies. Patients received two identical dropper bottles labelled morning or evening. For patients treated with timolol, both bottles contained timolol, whereas for those treated with latanoprost, one contained the vehicle. A total of 1256 patients were included in the analysis. Withdrawals varied from $0 \%$ to $11 \%$. The range of mean ages was from 46 to 67 years. Of the data available on sex, 597 of the patients were male and 593 were female. Of the data available on types of glaucoma, 410 subjects had primary open angle glaucoma (POAG), 465 ocular hypertension $(\mathrm{OH})$, and 137 other types of chronic open angle glaucoma (others). IOP was used as the primary outcome for efficacy in all of the studies included in the metaanalysis. Baseline and end point IOP were summarised in Table 2 .

\section{Efficacy-IOP reduction}

The percentage reductions in IOP with latanoprost and timolol at various time points are shown in Table 3. Both drugs significantly decreased IOP. Latanoprost showed better IOP lowering effects than timolol with an additional $4-7 \%$ reduction. The differences were all statistically significant except for the result from a single 12 month study (Fig 2).

\section{SIDE EFFECTS}

\section{(1) Short term}

Latanoprost caused hyperaemia and iris pigmentation in more patients than timolol (Table 4). The risk for hyperaemia was over twice that seen with timolol $(\mathrm{RR}=2.20,95 \%$ CI 1.33 , 3.65). The number needed to harm was 21 $(14,42)$ relative to timolol. Treating 21 patients with latanoprost will on average lead to one more patient developing hyperaemia. Moreover, of 478 patients who were treated 
Table 3 Percentage IOP reduction from baseline with latanoprost and timolol

\begin{tabular}{|c|c|c|c|c|}
\hline \multirow[b]{2}{*}{ Trial } & \multicolumn{2}{|c|}{ Percentage IOP reduction (mean (SE)) } & \multirow{2}{*}{$\begin{array}{l}\text { Difference of the reduction } \\
(95 \% \mathrm{CI})\end{array}$} & \multirow[b]{2}{*}{$p$ Value } \\
\hline & Latanoprost & Timolol & & \\
\hline \multicolumn{5}{|l|}{1 week } \\
\hline Diestelhorst et al $1998^{32}$ & $19.8(6.2)$ & $11.3(5.4)$ & $8.5(-7.6,24.7)$ & 0.30 \\
\hline Nicolela et al $1996^{35}$ & $25.5(5.8)$ & $19.8(5.3)$ & $5.62(-9.9,21.1)$ & 0.48 \\
\hline Rulo et al $1994^{36}$ & $31.2(2.8)$ & $24.4(2.9)$ & $6.85(-1.0,14.7)$ & 0.09 \\
\hline Pooled & $28.7(2.3)$ & $21.2(2.3)$ & $6.9(0.4,13.4)$ & 0.04 \\
\hline$\chi_{\text {heter }}^{2}$ & 3.16 & 4.59 & 0.07 & \\
\hline \multicolumn{5}{|l|}{$\begin{array}{l}\chi \text { heter } \\
1 \text { month }\end{array}$} \\
\hline Diestelhorst et al $1998^{32}$ & $19.4(5.6)$ & $8.5(2.4)$ & $11.0(-0.9,22.8)$ & 0.07 \\
\hline Mishima et al $1996^{34}$ & $24.1(1.3)$ & $19.9(1.1)$ & $5.2(1.9,8.4)$ & 0.00 \\
\hline Watson et al $1996^{37}$ & $34.3(1.5)$ & $34.0(1.5)$ & $0.4(-3.9,4.6)$ & 0.86 \\
\hline Pooled & $27.3(4.0)$ & $20.9(6.3)$ & $3.8(1.2,6.3)$ & 0.00 \\
\hline$\chi_{\text {heter }}^{2}$ & $24.64^{\star \star}$ & $94.22^{\star \star}$ & 4.57 & \\
\hline \multicolumn{5}{|l|}{3 months } \\
\hline Alm et al $1995^{27}$ & $33.7(2.6)$ & $29.7(1.7)$ & $4.0(-2.1,10.1)$ & 0.20 \\
\hline Aquino et al $1999^{28}$ & $37.1(4.0)$ & 31.7 (3.8) & $5.41(-5.5,16.3)$ & 0.16 \\
\hline Mastropasqua et al $1999^{33}$ & $24.9(2.9)$ & $21.7(2.8)$ & $3.2(-4.7,11.1)$ & 0.42 \\
\hline Mishima et al $1996^{34}$ & $26.8(1.3)$ & $19.0(1.1)$ & $7.8(-4.4,11.2)$ & 0.00 \\
\hline Watson et al $1996^{37}$ & $34.7(1.4)$ & $32.8(1.5)$ & $1.9(-2.2,6.1)$ & 0.37 \\
\hline Pooled & $31.2(2.3)$ & $26.9(3.4)$ & $5.0(2.8,7.3)$ & 0.00 \\
\hline$\chi_{\text {heter }}^{2}$ & $24.01^{\star \star}$ & $65.50^{\star \star}$ & 4.97 & \\
\hline \multicolumn{5}{|l|}{$\begin{array}{l}\chi_{\text {heter }} \\
6 \text { months }\end{array}$} \\
\hline Alm et al $1995^{27}$ & $32.1(2.6)$ & $27.2(1.7)$ & $4.8(-1.3,11.0)$ & 0.12 \\
\hline Camras et al $1996^{29}$ & $26.5(1.2)$ & $19.4(1.0)$ & $7.1(4.0,10.2)$ & 0.00 \\
\hline Mastropasqua et al $1999^{33}$ & $24.5(4.3)$ & $20.0(3.0)$ & $4.5(-5.7,14.8)$ & 0.39 \\
\hline Watson et al $1996^{37}$ & $34.7(1.4)$ & $33.2(1.5)$ & $1.5(-2.8,5.6)$ & 0.47 \\
\hline Pooled & $29.9(2.6)$ & $25.0(3.7)$ & $5.0(2.8,7.3)$ & 0.00 \\
\hline$\chi_{\text {heter }}^{2}$ & $21.14^{\star \star}$ & $64.61^{\star \star}$ & 4.57 & \\
\hline \multicolumn{5}{|l|}{12 months } \\
\hline Mastropasqua et al $1999^{33}$ & $24.1(4.6)$ & $19.2(3.1)$ & $4.9(-5.9,15.8)$ & 0.37 \\
\hline
\end{tabular}

$\mathrm{IOP}=$ introcular pressure. Percentage IOP reduction $=($ baseline IOP - end point IOP $) /$ baseline IOP $\times 100 \% . \mathrm{SE}=$ standard error. $\chi_{\text {heter }}^{2}=\chi^{2}$ test statistic for heterogeneity. ${ }^{\star \star} \mathrm{p}<0.001$, random effects model were used for pooling.

Favours timolol

Favours latanoprost

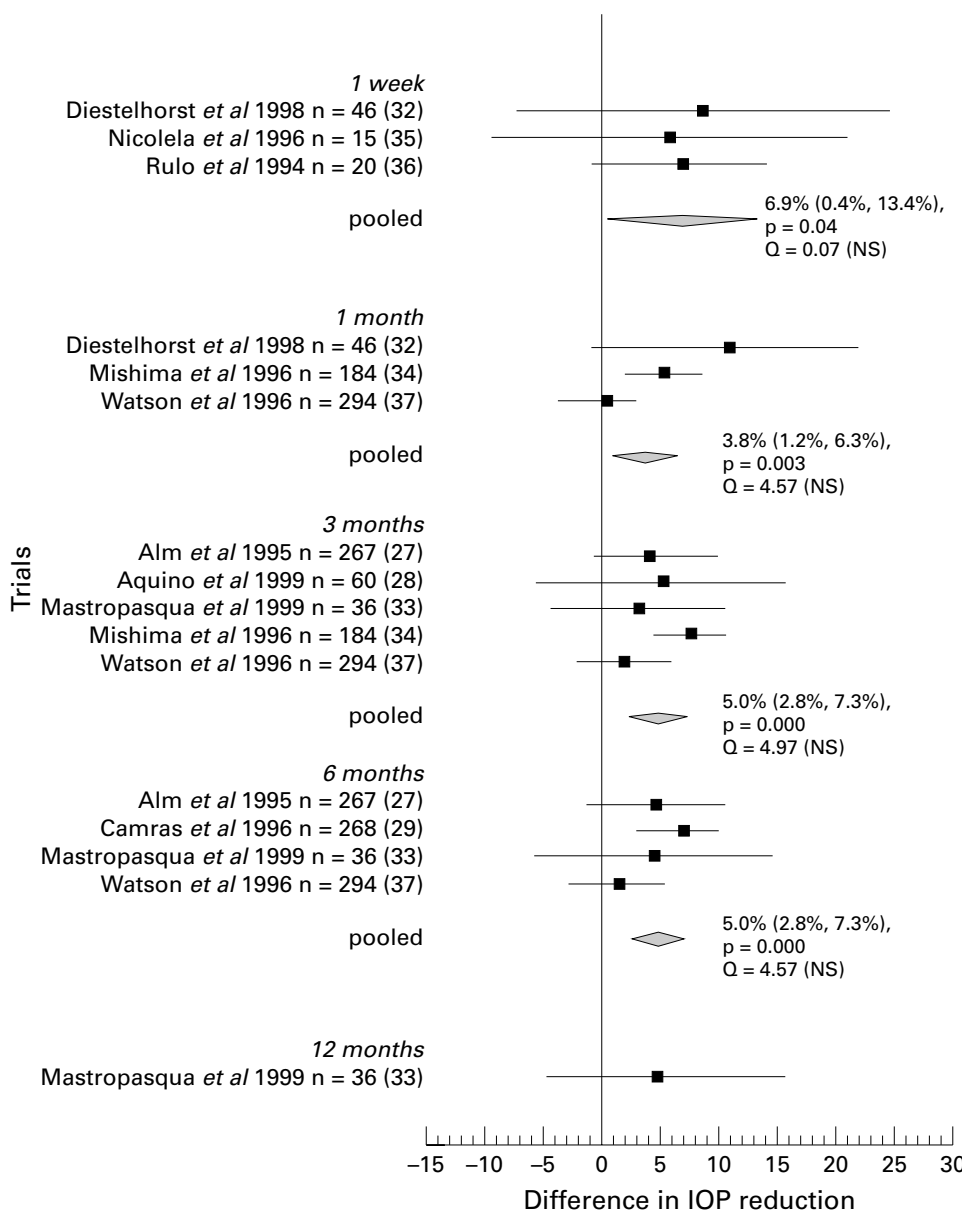

Figure 2 Difference in percentage IOP reduction from baseline between latanoprost and timolol. Mean difference and associated 95\% confidence interval (- - $. I O P=$ intraocular pressure; $Q=$ statistic of $\chi^{2}$ test for heterogeneity; $N S=$ no statistical heterogeneity. Numbers in parentheses are references. with latanoprost, 21 (4.39\%) developed iris pigmentation. In contrast, none of the patients treated with timolol showed this effect $(0 / 387)$.

(2) Long term

Three studies ${ }^{24-26}$ explored the long term iris darkening effects of latanoprost for up to 2 years after the randomised controlled blinded phases. ${ }^{27} 2937$ The risks of iris pigmentation are shown in Figure 3.

There was an increased incidence of pigmentation with time although in none of the studies did the difference reach statistical significance at the usual 5\% level. The iris pigmentation appears more likely to be with brownish mixed iris colour eyes and this may explain the apparently different incidence rates in the different countries (Table 5).

Four studies compared systemic adverse reactions to timolol versus latanoprost, such as their effects on systolic blood pressure and heart rate. Timolol caused slowing of heart rate after 3 or 6 months of treatment (Table 6), and this returned to the baseline level after switching to latanoprost. ${ }^{25}$

\section{EFFECTS OF DIFFERENT REGIMENS OF}

LATANOPROST

The evening regimen was compared with the morning regimen of latanoprost (Table 7 ). The pooled percentage IOP reductions (mean (SE)) were 33.2 (1.4) and 28.1 (1.1) for the evening regimen and the morning regimen respectively. The pooled difference was $5.1 \%$ $(\mathrm{p}=0.006)$ (Table 7).

In addition, the once daily evening regimen of latanoprost was compared with the twice daily regimen (Table 8 ). Although the evening regimen was marginally better than the twice daily regimen $(\mathrm{p}=0.08)$ in one of the trials, pooling with other trials produced numerically 
Table 4 Risk of side effects with latanoprost and timolol

\begin{tabular}{|c|c|c|c|c|c|c|}
\hline \multirow[b]{2}{*}{ Side effects } & \multirow{2}{*}{$\begin{array}{l}\text { No of } \\
\text { trials }\end{array}$} & \multicolumn{2}{|c|}{ Crude event rate } & \multirow[b]{2}{*}{$R R(95 \% C I)$} & \multirow[b]{2}{*}{$R D(95 \% C I)$} & \multirow[b]{2}{*}{ NNH $(95 \% C I)$} \\
\hline & & Latanoprost & Timolol & & & \\
\hline Withdrawals due to adverse effects & 2 & $9 / 277$ & $14 / 285$ & $0.70(0.30,1.66)$ & $-0.02(-0.05,0.16)$ & NA \\
\hline Hyperaemia & 6 & $51 / 586$ & $20 / 503$ & $2.20(1.33,3.65)^{\star \star}$ & $0.05(0.02,0.07)^{\star \star}$ & $21(14,42)^{\star \star}$ \\
\hline Conjunctivitis & 3 & $7 / 419$ & $5 / 320$ & $0.80(0.25,2.53)$ & $0.006(-0.001,0.02)$ & NA \\
\hline Increased pigmentation & 4 & $21 / 478$ & $0 / 387 \dagger$ & $8.01(1.87,34.30)^{\star}$ & $0.03(0.01,0.04)^{\star \star}$ & $36(22,91)^{\star \star}$ \\
\hline Hypotension & 1 & $0 / 149 \dagger$ & $2 / 145$ & $0.19(0.01,4.02)$ & $-0.01(-0.04,0.01)$ & NA \\
\hline Bradycardia & 1 & $0 / 87 \dagger$ & $2 / 91$ & $0.21(0.01,4.29)$ & $-0.02(-0.06,0.02)$ & NA \\
\hline
\end{tabular}

$\mathrm{RR}=$ relative risk $\mathrm{RD}=$ risk difference or attribute risk; $\mathrm{NNH}=$ number needed to harm; $\mathrm{CI}=$ confidence interval.

†For trials with event rate of zero, 0.5 was added to each cell of the individual $2 \times 2$ table to calculate RR, RD, or NNH.

${ }^{\star} \mathrm{p} \leqslant 0.05,{ }^{\star \star} \mathrm{p} \leqslant 0.01$.

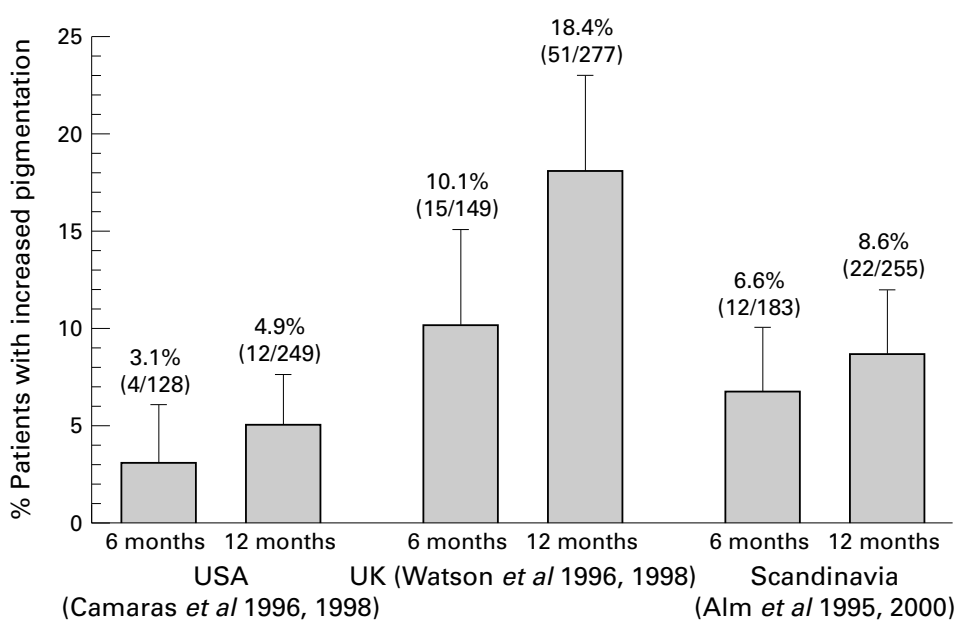

Figure 3 Percentage of patients with increased iris pigmentation after use of latanoprost. Error bar shows $95 \%$ confidence intervals.

but not statistically different IOP reductions $(5.5 \%, \mathrm{p}=0.17)$ (Table 8).

SENSITIVITY ANALYSES

Sensitivity analyses were undertaken to evaluate the effect of quality of randomised controlled trials in terms of the study design and withdrawal rate. Trials designed as double blind parallel, double blind crossover, and single blind parallel studies were stratified and the percentage IOP reduction between latanoprost and timolol were compared. There were no statistically significant differences between the groups. In addition, we divided the studies into two groups according to withdrawal rate (less than $10 \%$ and more than $10 \%$ ). The results showed that the withdrawal rate was not a significant factor (Table 9).

\section{Discussion}

Glaucoma which causes optic nerve damage and visual field loss is the most important cause of irreversible blindness worldwide. About 66.8 millions people have glaucoma, 6.7 million of whom are bilaterally blind. ${ }^{38}$

Pharmacological treatments for glaucoma aim to lower IOP and thereby reduce the risk of optic nerve damage. Studies have shown that reduction of IOP prevents development of glaucoma or visual field loss ${ }^{39-41}$ and indeed if the IOP is substantially lowered through treatment, the rate of progression of glaucoma is reduced even among those patients with normal tension glaucoma. ${ }^{42}$

Latanoprost is one of the first prostaglandins to be used on a chronic basis in glaucoma patients. Our meta-analysis based on 11

Table 5 Number of patients with increased pigmentation with long term treatment of latanoprost

\begin{tabular}{|c|c|c|c|c|c|c|}
\hline \multirow[b]{2}{*}{ Iris colour } & \multicolumn{2}{|c|}{$U S A, 1$ year experience ${ }^{25}$} & \multicolumn{2}{|c|}{$U K, 2$ year experience ${ }^{26}$} & \multicolumn{2}{|c|}{ Scandinavia, 2 year experience ${ }^{24}$} \\
\hline & No & Increased pigmentation (\%) & No & Increased pigmentation (\%) & No & Increased pigmentation (\%) \\
\hline Blue/grey & 21 & $0(0)$ & 27 & $0(0)$ & 89 & 0 \\
\hline Blue/grey with slightly brown & 36 & $0(0)$ & 76 & $1(1)$ & 89 & $1(1)$ \\
\hline Blue/grey-brown & 34 & $3(9)$ & 79 & $12(15)$ & 33 & $5(15)$ \\
\hline Green with slightly brown & 4 & $0(0)$ & 2 & $0(0)$ & 3 & $0(0)$ \\
\hline Green-brown & 46 & $6(12)$ & 70 & $34(49)$ & 31 & $14(45)$ \\
\hline Yellow-brown & 23 & $3(13)$ & 3 & $2(67)$ & 2 & $2(100)$ \\
\hline Brown & 80 & $0(0)$ & 20 & $2(10)$ & 7 & $0(0)$ \\
\hline Total & 247 & $12(5)$ & 277 & $51(18)$ & 255 & $22(9)$ \\
\hline
\end{tabular}

Table 6 Mean reduction of systemic blood pressure and heart rate and their $95 \%$ confidence intervals after using timolol or latanoprost

\begin{tabular}{|c|c|c|c|c|c|c|}
\hline \multirow[b]{2}{*}{ Trial } & \multicolumn{3}{|l|}{ Timolol } & \multicolumn{3}{|l|}{ Latanoprost } \\
\hline & Systolic $\mathrm{BP}(\mathrm{mm} \mathrm{Hg})$ & Diastolic BP (mm Hg) & Heart rate (beats/min) & Systolic BP $(\mathrm{mm} \mathrm{Hg})$ & Diastolic BP (mm Hg) & $\begin{array}{l}\text { Heart rate } \\
\text { (beats } / \mathrm{min} \text { ) }\end{array}$ \\
\hline \multicolumn{7}{|l|}{ Camras et al $1996^{29}$} \\
\hline 2 weeks & $2.0(-2.3,6.3)$ & $0.0(-2.3,2.3)$ & $2(0,4)$ & $1.0(-3.2,5.2)$ & $0.0(-2.6,2.6)$ & $1(-2,4)$ \\
\hline 3 months & $3.0(-1.4,7.4)$ & $0.0(-2.3,2.3)$ & $4(2,6)^{\star \star}$ & $0.0(-4.3,4.3)$ & $0.0(-2.4,2.4)$ & $2(-1,5)$ \\
\hline 6 months & $3.0(-1.4,7.4)$ & $0.0(-2.6,2.6)$ & $4(2,6)^{\star \star}$ & $0.0(-4.4,4.4)$ & $0.0(-2.6,2.6)$ & $1(-2,4)$ \\
\hline \multicolumn{7}{|l|}{ Drance et al $1998^{30}$} \\
\hline 3 weeks & $5.0(1.5,8.5)$ & $2.0(0.2,4.2)$ & 1 & $-0.6(-4.1,2.9)$ & $-0.4(-2.4,1.6)$ & I \\
\hline Nicolela et al $1996^{35}$ & & & & & & \\
\hline 1 week & $1.3(-12.6,15.2)$ & $0.2(-7.7,8.1)$ & $0(-8,8)$ & $1.8(-11.3,14.9)$ & $0.3(-7.3,7.9)$ & $5(-8,18)$ \\
\hline \multicolumn{7}{|l|}{ Watson et al $1996^{37}$} \\
\hline 6 months & / & / & $2(-1,5)$ & / & / & / \\
\hline
\end{tabular}

$\mathrm{BP}=$ blood pressure

${ }^{\star \star} \mathrm{p}<0.01$. 
Table 7 Percentage IOP reduction from baseline with evening regimen and morning regimen of latanoprost (3 month treatment)

\begin{tabular}{|c|c|c|c|c|}
\hline \multirow[b]{2}{*}{ Trial } & \multicolumn{2}{|c|}{$\begin{array}{l}\text { Percentage IOP reduction (mean } \\
(S E) \text { ) }\end{array}$} & \multirow{2}{*}{$\begin{array}{l}\text { Difference of } \\
\text { IOP reduction }\end{array}$} & \multirow[b]{2}{*}{ p Value } \\
\hline & Evening & Morning & & \\
\hline Alm et al $1995^{27}$ & $35.7(1.6)$ & $31.0(2.0)$ & $4.6(2.6)$ & 0.08 \\
\hline Alm et al $1995^{45}$ & $36.7(3.6)$ & / & / & 1 \\
\hline Mastropasqua et al $1999^{33}$ & $24.9(2.9)$ & l & I & 1 \\
\hline Mishima et al $1996^{34}$ & / & $26.8(1.3)$ & 1 & 1 \\
\hline Watson et al $1996^{37}$ & $34.7(1.4)$ & / & I & I \\
\hline Pooled & $33.2(1.4)$ & $28.1(1.1)$ & $5.1(1.8)$ & 0.006 \\
\hline$\chi_{\text {heter }}^{2}$ & $12.00^{\star \star}$ & 3.02 & $/$ & / \\
\hline
\end{tabular}

IOP $=$ introcular pressure.

Percentage IOP reduction $=($ baseline IOP - end point IOP $) /$ baseline IOP $\times 100 \%$.

$\mathrm{SE}=$ standard error.

$\chi_{\text {heter }}^{2}=\chi^{2}$ test statistic for heterogeneity.

${ }^{\star \star} \mathrm{p}<0.001$, random effects model were used for pooling.

Table 8 Percentage IOP reduction from baseline with evening regimen and twice daily (bid) regimen of latanoprost (3 month treatment)

\begin{tabular}{|c|c|c|c|c|}
\hline \multirow[b]{2}{*}{ Trial } & \multicolumn{2}{|c|}{ Percent IOP reduction (mean (SE)) } & \multirow{2}{*}{$\begin{array}{l}\text { Difference of } \\
\text { IOP reduction }\end{array}$} & \multirow[b]{2}{*}{$p$ Value } \\
\hline & Evening & Twice daily & & \\
\hline Alm et al $1995^{27}$ & $35.7(1.7)$ & l & / & / \\
\hline Alm et al $1995^{45}$ & $36.7(3.6)$ & $27.7(3.7)$ & $9.0(5.2)$ & 0.08 \\
\hline Mastropasqua et al $1999^{33}$ & $24.9(2.9)$ & 1 & 1 & 1 \\
\hline Watson et al $1996^{37}$ & $34.7(1.4)$ & / & / & / \\
\hline Pooled & $33.2(1.4)$ & $27.7(3.7)$ & $5.5(4.0)$ & 0.17 \\
\hline$\chi_{\text {heter }}^{2}$ & $12.00^{\star \star}$ & / & 1 & I \\
\hline
\end{tabular}

IOP $=$ introcular pressure.

Percentage IOP reduction $=($ baseline IOP - end point IOP $) /$ baseline IOP $\times 100 \%$.

$\mathrm{SE}=$ standard error .

$\chi_{\text {heter }}^{2}=\chi^{2}$ test statistic for heterogeneity.

${ }^{\star \star} \mathrm{p}<0.001$, random effects model were used for pooling.

Table 9 Sensitivity analysis to evaluate the effect of quality of randomised controlled trials on IOP reduction between latanoprost and timolol

\begin{tabular}{lll}
\hline & $\begin{array}{l}\text { Difference in percentage IOP } \\
\text { reduction }\end{array}$ & $\begin{array}{l}95 \% \text { Confidence } \\
\text { intervals }\end{array}$ \\
\hline Design of trial & & \\
$\quad$ All trials & 6.0 & $4.3,7.8$ \\
$\quad$ Double blind, parallel & 6.0 & $4.2,7.8$ \\
$\quad$ Double blind, crossover & 5.6 & $-9.9,21.1$ \\
$\quad$ Single blind, parallel & 6.8 & $-1.0,14.7$ \\
Withdrawals & & $4.3,7.8$ \\
$\quad$ All trials & 6.0 & $3.3,7.5$ \\
Withdrawals $\leqslant 10 \%$ & 5.4 & $4.4,11.2$ \\
$\quad$ Withdrawals $>10 \%$ & 7.8 & \\
\hline
\end{tabular}

All pooling was undertaken using fixed effect model as no heterogeneity was detected by $\mathrm{Q}$ test.

published clinical trials shows that $0.005 \%$ latanoprost applied topically once daily is superior to $0.5 \%$ timolol twice daily in reducing IOP. Latanoprost brings about an additional $5 \%$ decrease in IOP $(95 \%$ CI $3 \%$, $7 \%)$, or an average $1.6 \mathrm{~mm} \mathrm{Hg}(\mathrm{p}<0.001)$ further lowering in IOP when compared to timolol. The studies include both company sponsored and non-company sponsored RCTs and were undertaken in various countries including North America (USA and Canada), Asia (Japan and Philippines), and Europe (UK, Germany, Holland, Italy, and Scandinavia). The results are similar to those of a previous meta-analysis of eight company sponsored studies, which demonstrated that latanoprost produced an additional $1.7 \mathrm{~mm} \mathrm{Hg}(\mathrm{p}<0.001)$ reduction in IOP compared with timolol. ${ }^{43}$

It has been suggested that the time of IOP measurement is important when comparing latanoprost with timolol. ${ }^{37}$ The peak IOP reducing effect of latanoprost is reached 8-12 hours after the drug has been administered, and at this time point timolol is at trough values. ${ }^{37}$ Therefore, a single time measurement of IOP in the morning - for example, at $9 \mathrm{am}$, would catch the peak value of latanoprost but not the trough value of timolol when both are administered the previous evening. In order to avoid such bias, we calculated the mean value of IOP measured in the morning, noon, and afternoon for our analysis except for the Japanese trial, which only measured IOP in the morning. In the Japanese trial, although the IOP was measured in the morning at 9 am, latanoprost was comparable with timolol because it was administered in the morning while the second dose of timolol was administered in the evening. The comparison therefore presented trough values for both drugs.

Alm et $a l^{77}$ compared evening and morning administrations of latanoprost and found that the evening application was more effective than the morning application at 3 months but not at 6 months. This may be caused by carryover effect from the crossover design. Konstas et $a l^{44}$ also failed to establish the superiority of an evening regimen over a morning regimen from his 2 month crossover study. To exclude carryover effect, only the results from the first period before crossover were used to compare the two treatment regimens (Table 7). The results confirm that the once daily evening regimen of $0.005 \%$ latanoprost is superior to the once daily morning regimen.

Poor compliance is a major problem with most topical agents in the treatment of open angle glaucoma because they usually require at least three times daily administrations. In contrast, latanoprost only needs a once daily administration. Some studies have compared the once daily regimen with the twice daily regimen of this agent and did not find any statistical difference with the same concentration. ${ }^{45}$ Others have reported the superiority of the higher concentration of latanoprost $(0.005 \%)$ once daily over the lower concentration of latanoprost $(0.0015 \%) .^{31}{ }^{46}$ Our metaanalysis shows no statistically significant difference in IOP reductions between the two regimens of $0.005 \%$ latanoprost twice daily. Thus, once daily application appears adequate for this agent. This is obviously due to the longer action of latanoprost, which may be particularly useful for the elderly. Compliance should be good but comparative data with other treatments are necessary.

Unlike $\beta$ blockers and some other currently used medications such as carbonic anhydrase inhibitors and $\alpha_{2}$ agonists, latanoprost acts on outflow rather than formation of aqueous humour. ${ }^{478}$ Because latanoprost increases uveoscleral outflow, ${ }^{48}$ it can theoretically reduce IOP below episcleral venous pressure. This may be advantageous in patients with normal tension glaucoma. In fact, one trial ${ }^{30}$ suggested that $0.005 \%$ latanoprost produced better lowering of ocular perfusion pressure than $0.5 \%$ timolol in normal tension glaucoma. Latanoprost may reduce IOP without reducing systemic blood pressure. In contrast, timolol may reduce both of these.

Bradycardia $^{49-51}$ and bronchospasm ${ }^{52-54}$ caused by ophthalmic timolol have been 
reported in patients with cardiovascular or pulmonary disorders. Therefore, caution is necessary in the use of timolol in such patients. In contrast, latanoprost does not alter heart rate and blood pressure, ${ }^{29}{ }^{30} 35$ and does not affect respiratory function in asthmatic patients. ${ }^{55}$ The major adverse reaction to latanoprost is an increase in iris pigmentation. This risk may be as high as $18 \%$ within a 2 year period and varies according to the types of iris colour (Table 5). The iris darkening associated with latanoprost may reflect induction of tyrosinase, the rate limiting enzyme in the formation of melanin. ${ }^{56}$ Latanoprost does not induce iris melanocyte mitosis. ${ }^{57}$ While recent evidence suggests that the problem is purely cosmetic, ongoing surveillance is necessary.

UK prices suggest that if we adopt a conservative approach and assume that latanoprost once daily and timolol twice daily are equivalent in effectiveness, latanoprost is three times more expensive than timolol. However, a rigorous economic evaluation considering differences in both efficacy and side effects of these two agents is required. Intercountry differences in prices will obviously also need to be considered.

In summary, latanoprost is superior to timolol for reducing intraocular pressure. Increase in iris pigmentation is still a concern. For patients in whom timolol is contraindicated, latanoprost is in our view a suitable alternative.

1 Coyle D, Drummond M. The economic burden of glaucoma in UK. PharmacoEconomics 1995;7:484-9.

2 Diggory P, Cassels-Brown A, Vail A, et al. Avoiding unsuspected respiratory side-effects of topical timolol with cardioselective or sympathomimetic agents. Lancet 1995 345:1604-6.

3 Fishman WH, Fuksbrumer MS, Tannenbaum M. Topical ophthalmic beta-adrenergic blockade for the treatment of glaucoma and ocular hypertension. F Clin Pharmacol 1994 34:795-803.

4 McMahon CD, Shaffer RN, Hoskins HD, et al. Adverse effects experienced by patients taken timolol. $\mathrm{Am} \mathcal{F}$ Ophthalmol 1979;88:736-8.

5 Calissendorff B, Maren N, Wetrell K, et al. Timolol versus pilocarpine separately or combined with acetazolamidepilocarpine separately or combined with acetazolamideeffects on

6 Zadok D, Geyer O, Zadok J, et al. Combined timolol and pilocarpine alone and timolol alone in the treatment of glaucoma. Am f Ophthalmol 1994;117:728-31.

7 Jadad AR, Moore RA, Carroll D, et al. Assessing the quality of randomised clinical trials: is blinding necessary. Contro Clin Trials 1996;17:1-12.

8 Zhang WY, Li Wan Po A. Analgesic efficacy of paracetamol and of its combination with codeine and caffeine in surgical pain - a meta-analysis. F Clin Pharm Ther 1996;21:26182.

9 Rothman KJ. Modern epidemiology. Boston: Little, Brown, 1986:177-233

10 DerSimonian R, Laird N. Meta-analysis in clinical trials. Controlled Clinical Trials 1986;7:177-88.

11 Cook RJ, Sackett DL. The number needed to treat: a clinically useful measure of treatment effect. BMF 1995;320: cally usefu.

12 Whitehead A, Whitehead J. A general parametric approach to the meta-analysis of randomised clinical trials. Stat Med 1991;10:1665-77

13 Aung T, Wong HT, Yip CC, et al. A randomised double-masked study comparing latanoprost with timolo in patients with chronic angle-closure glaucoma. The Association for Reearch in Vision and Ophthalmology (ARVO) meeting. Fort Lauderdale, Florida, USA, May 9-14, 1999.

14 Konstas AG, Maltezos A, Gandi S, et al. Comparison of 24-hour intraocular pressure reduction with two dosing regimens of latanoprost and timolol maleate in patients with primary open-angle glaucoma. Am $\mathcal{f}$ Ophthalmol with primary open

15 Stewart WC, Day DG, Sharp ED, et al. Efficacy and safety of timolol solution once daily vs timolol gel added to of timolol solution once daily vs timolol gel
latanoprost. Am $\mathcal{f}$ Ophthalmol 1999;128:629-6.

16 Bucci MG. Intraocular pressure-lowering effects of latanoprost monotherapy versus latanoprost or pilocarpine in comparison with timolol: a randomised, observer-masked multicenter study in patients with open-angle glaucoma. $\mathcal{F}$ Glaucoma 1999;8:24-30.

17 Racz P, Ruzsonyi MR, Nagy ZT, et al. Around-the-clock intraocular pressure reduction with once-daily application of latanoprost by itself or in combination with timolol. Arch Ophthalmol 1996;114:268-73.

18 Alm A, Widengard I, Kjellgren D, et al. Latanoprost administered once daily caused a maintained reduction of intraocular pressure in glaucoma patients treated concomitantly with timolol. Br $\mathcal{f}$ Ophthalmol 1995;79:12-6.

19 Camras CB, Alm A, Watson P, et al. Latanoprost, a prostaglandin analog, for glaucoma therapy. Efficacy and safety after 1 year of treatment in 198 patients. Ophthalmology 1996;103:1916-24.

20 Alm A. Comparison phase III clinical trial of latanoprost and timolol in patients with elevated intraocular pressure. Adv Prostaglandin, Theomboxane, E Leukotriene Res 1995; 23:527-32.

21 Fristrom B. A 6-month, randomised, double-masked comparison of latanoprost with timolol in patients with open angle glaucoma or ocular hypertension. Acta Ophthalmol Scand 1996;74:140-4.

22 Thygesen J, Aaen K, Theodorsen F, et al. Short-term effect of latanoprost and timolol eye drops on tear fluid and the ocular surface in patients with primary open-angle glaucoma and ocular hypertension. Acta Ophthalmol Scand 2000;78:37-44.

23 Orzalesi N, Rossetti L, Invernizzi T, et al. A comparison of the effect of timolol, latanoprost, and dorzolaminde on circadian intraocular pressure in patients with glaucoma or ocular hypertension. Association for Research in Vision and Ophthalmology (ARVO) meeting. Fort Lauderdale, Florida, USA, 9-14 May 1999

24 Alm A, Widengard I. Latanoprost: experience of 2-year treatment in Scandinavia. Acta Ophthalmol Scand 2000;78: $71-6$.

25 Camras CB and the US Latanoprost Study Group. Latanoprost treatment for glaucoma: effects of treating for 1 year and of switching from timolol. Am f Ophthalmol 1998;126: 390-9.

26 Watson PG, Alvarado JA. Latanoprost: two years' experience of its use in the United Kingdom. Ophthalmology 998; 105:82-7.

27 Alm A, Stjernschantz J, the Scandinavian Latanoprost Study Group. Effects on intraocular pressure and side effects of $0.005 \%$ latanoprost applied once daily, evening or morning - a comparison with timolol. Ophthalmology 1995; 102:1743-52.

28 Aquino MV, Lat-Luna M. The effect of latanoprost vs timolol on intraocular pressure in patients with glaucoma and ocular hypertension. Asian $\mathcal{F}$ Ophthalmol 1999;1:3-7.

29 Camras CB and the US Latanoprost Study Group. Comparison of latanoprost and timolol in patients with ocular hypertension and glaucoma. A six-month, masked, multicenter trial in the United States. Ophthalmology 1996; 103:138-47.

30 Drance SM, Crichton A, Mills RP. Comparison of the effect of latanoprost $0.005 \%$ and timolol $0.5 \%$ on the calculated ocular perfusion pressure in patients with normal-tension glaucoma. Am f Ophthalmol 1998;125:585-92.

31 Diestelhorst M, Roters S, Krieglstein GK. The effect of latanoprost $0.005 \%$ once daily versus $0.0015 \%$ twice daily on intraocualr pressure and aqueous humor protein concentration in glaucoma patients. A randomised, doublemasked comparison with timolol 0.5\%. Graefes Arch for Clin Exp Ophthalmol 1997;235:20-26.

32 Diestelhorst $M$. Almegard B. Comparison of two fixed combinations of latanoprost and timolol in open-angle
glaucoma. Graefes Arch Clin Exp Ophthalmol 1998;236: glaucoma.

33 Mastropasqua L, Carpineto P, Ciancaglini A, et al. A 12 -month, randomised, double-masked study comparing latanoprost with timolol in pigmentary glaucoma. Ophthalmology 1999;106:550-5.

34 Mishima HK, Masuda K, Kitazawa Y, et al. A comparison of latanoprost and timolol in primary open-angle glaucoma and ocular hypertension: a 12-week study. Arch Ophthalmol 1996;114:929-32.

35 Nicolela MT, Buckley AR, Walman BE, et al. A comparative study of the effects of timolol and latanoprost on blood flow velocity of the retrobulbar vessels. Am $f$ Ophthalmol 1996;122:784-9.

36 Rulo AH, Greve EL, Hoyng PF. Additive effect of latanoprost, a prostaglandin $\mathrm{F}_{2 a}$ analogue, and timolol in
patients with elevated intraocular pressure. Br f Ophthalmol patients with elevated

37 Watson P, Stjernschantz J, Beck L, et al. A six-month, randomised, double-masked study comparing latanoprost with timolol in open-angle glaucoma and ocular hypertension. Ophthalmology 1996;103:126-37.

38 Alward WLM. Medical management of glaucoma. $N$ Engl F Med 1998;339:1298-360.

39 Ontoso IA, Grima FG, Ontoso EA, et al. Does medical treatment of mild intraocular hypertension prevent glaucoma. Eur F Epidemiolol 1997; 13:19-23.

40 Kass MA. Timolol treatment prevents or delays glaucomatous visual field loss in individuals with ocular hypertension: a five year randomised double-masked, clinical trial. Trans Am Ophthalmol Soc 1990;87:598-618.

41 Hattenhauer MG, Johnson $\mathrm{DH}$, Ing $\mathrm{HH}$, et al. The probability of blindness from open-angle glaucoma. Ophthalmology 1998;105:2099-104. 
42 Collaborative Normal-Tension Glaucoma Study Group. Comparation of glaucomatous between untreated patients with normal-tension glaucoma and patiens with therapeutically reduced intraocular pressure. Am $\mathcal{f}$ Ophthalmo 1998;126:487-96.

43 Zimmerman T. Latanoprost in glaucoma management. Global Xalatan ${ }^{\circledR}$ (latanoprost) Expert Meeting, Hong Kong, 14 December 1999 .

44 Konstas AG, Maltezos A, Gandi S, et al. Comparison of 24-hour intraocular pressure reduction with two dosing regimens of latanoprost and timolol maleate in patients with primary open-angle glaucoma. Am $\mathcal{f}$ Ophthalmol 1999;128:15-20.

45 Alm A, Widengard I, Kjellgren D, et al. Latanoprost administered once daily caused a maintained reduction of intraocular pressure in glaucoma patients treated concomitantly with timolol. Br f Ophthalmol 1995;79:12-16.

46 Lusky M, Ticho U, Glovinsky J, et al. A comparative study of two dose regemens of latanoprost in patients with elevated intraocular pressure. Ophthalmology 1997;104:1720-4.

47 Camras CB. Mechanism of the prostaglandin-induced reduction of intraocular pressure in humans. In: Samuelsson B, Paoletti R, Ramwell PW, Vane JR, eds. Ad Prostaglandin Thromboxane Leukot Res, Vol 23. New York: Raven Press 1995:519-25.

48 Toris CB, Camras CB, Yablonski ME. Effects of PhXA41, a new prostaglandin $\mathrm{F}_{2 \alpha}$ analog on aqueous humor dynamics in human eyes. Ophthalmology 1993;100:1312-17.

49 Leier CV, Baker ND, Weber PA. Cardiovascular effects of ophthalmic timolol. Ann Intern Med 1986;104:197-9.
50 Dinai $\mathrm{Y}$, Sharir $\mathrm{M}$, Naveh NN, et al. Bradycardia induced by interaction between quinidine and ophthalmic timolol. Ann Intern Med 1985;103:890-1.

51 Pringle SD, MacEwen CJ. Severe bradycardia due to interaction of timolol eye drops and verapamil. BMF 1987;294: $155-6$.

52 Avorn J, Glynn RJ, Guiwitz JH. Adverse pulmonary effects of topical beta blockers used in the treatment of glaucoma. f Glaucoma 1993;2:158-65.

53 Jones FL Jr, Ekberg NL. Exacerbation of asthma by timolol. N Engl f Med 1979;301:270.

54 Nelson WL, Fraunfelder FT, Sills JM, et al. Adverse respiratory and cardiovascular events attributed to timolol ophthalmic solution, 1978-1985. Am f Ophthalmol 1986; 102:606-11.

55 Hedner J, Everts B, Moller CS. Latanoprost and respiratory function in asthmatic patients. Arch Ophthalmol 1999: 1305-9.

56 Lindsey JD, Jones HL, Weinreb RN. Latanoprost increases tyrosinase immunoreactivity in human irirs organ cultures. The Association for Research in Vision and Ophthalmology (ARVO) Meeting. Fort Lauderdale. Florida, USA, 9-14 May 1999.

57 Wang N, Lindsey JD, Jones HL, et al. Latanoprost does not induce mitosis in melanocytes within human iris organ cultures. The Association for Research in Vision and Ophthalmology (ARVO) Meeting. Fort Lauderdale, Florida, USA, 9-14 May 1999. 